\title{
Computer science and technology : historiography III
}

\author{
Camille Akmut
}

February 27, 2022

\footnotetext{
concrete

Black science fiction; virtual bodies; Community Memory project; more hacker magazines; counter-intelligence in Indonesia; conspiracies...
} 


\section{MONOGRAPHS}

- Kaiser, David. 2011. How the Hippies Saved Physics. W. W. Norton.

On the Fundamental Fysiks Group, associated with Berkeley : philosopher-physicists with some aspects of hacker groups, and influence on cyber culture (through Herbert and Sarfatti, contributors to e.g. Mondo magazine and its predecessors).

- Dery. Mark. 1994. "Black To The Future: Interviews...". circa 40 pages. In Dery (ed.) Flame Wars: The Discourse of Cyberculture. Duke University Press.

Examplary introductory essay that sets up theoretical problems and provides many examples. Defines Afrofuturism, as : "Speculative fiction that treats African-American themes and addresses African-American concerns in the context of twentieth-century technoculture-and, more generally, African-American signification that appropriates images of technology and a prosthetically enhanced future- might, for want of a better term, be called Afrofuturism." (p. 180, followed by an il. of 'Angry Black Man'). Interviews with Samuel Delany, Greg Tate and Tricia Rose.

Among quantities of, often fascinating, references are :

"Basquiat paintings such as Molasses (...); in movies such as John Sayles's The Brother from Another Planet and Lizzie Borden's Born in Flames; in records such as Jimi Hendrix's Electric Ladyland, George Clinton's Computer Games, Herbie Hancock's Future Shock, and Bernie Worrell's Blacktronic Science; and in the intergalactic big-band jazz [of] Sun Ra's Omniverse Arkestra, Parliament-Funkadelic's Dr. Seussian astrofunk, and Lee Perry's dub reggae (...) comics such as Milestone Media's Hardware [about] a black scientist (...) wag[ing] guerrilla war on his (...) employer."

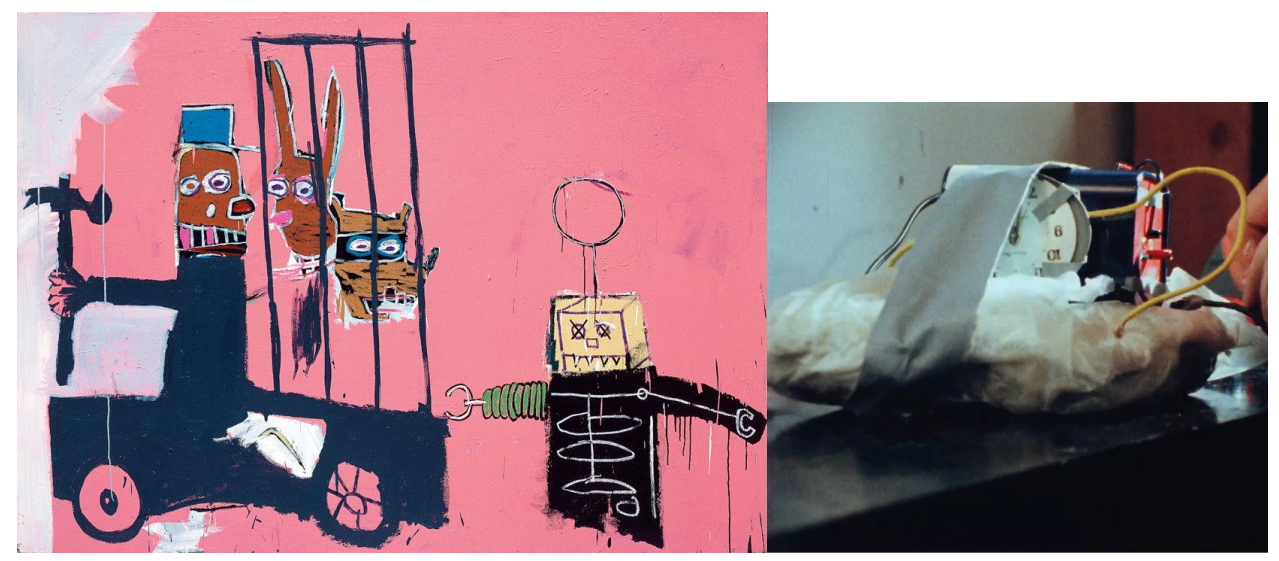

Illustration: Basquiat, 'Molasses' (1983) / Borden, Born in Flames (1983)

- Hayles, Katherine. 1999. How We Became Posthuman: Virtual Bodies in Cybernetics, Literature, and Informatics. Chic. Press

A research surrounding the body and its material loss, focusing on cybernetics among others (based on archives, interviews, specialized literature). 
"As early as the 1950s, Norbert Wiener proposed it was theoretically possible to telegraph a human being (...). The producers of Star Trek operate from similar premises when they imagine that the body can be dematerialized into an informational pattern and re-materialized, without change, at a remote location." [ch. 1]

(In the latter series the device is called transporter and the signal or process "beam", engineer-style staff are in charge and various episodes explore what happens if the procedure malfunctions.)

It has three components :

"The first centers on how information lost its body, that is, how it came to be conceptualized as an entity separate from the materialforms in which it is thought to be embedded. The second story concerns how the cyborg was created as a technological artifact and cultural icon in the years following World War II. The third (...) is the unfolding story of how a historically specific construction called the human is giving way to a different construction called the posthuman." [ibid]

- Stephenson, Neal. 1999. In the Beginning was the Command Line. cryptonomicon.com

Jobs and Wozniak sold computers for homes; Bill Gates and Paul Allen sold operating systems. "This was much weirder", "A computer at least had some sort of physical reality to it."

\section{ARTICLES}

- Colstad and Lipkin, and Rossman. 1975. Community Memory articles in ACM Computers \& Society 6(4): 6 ff.

Instructions for this democratic system were reported to be as follows,

"To use Community Memory, the user would type the command ADD, followed by the text of the item, and then by any keywords under which he desired the item to be indexed. To search for an item, the user would type the command FIND (...)"

A pilot network was set up in the San Francisco Bay area. "(...) this system was installed without fanfare adjacent to a bulletin board in a non-profit community record and music store in Berkeley. People were delighted by the chance to, put a computer to use"

Rossman notes : "The system is inescapably political. Its politics are concerned with people's power - their power with respect to the information useful to them, their power with respect to the technology of information (hardware and software both)." long before other projects such as free software.

\section{NEWSPAPER ARTICLES}

- Lashmar et al. 2021. "Slaughter in Indonesia: Britain's secret propaganda war". The Guardian, 17/10.

Hidden some, appearing at the end of the article is the mention that Indonesia was "among many third world countries using equipment supplied by Swiss-based company 
Crypto AG." Thus : "GCHQ could break and read Indonesian codes without difficulty." The broader context being the destabilization of Sukarno's government, and the following mass killings of millions of communists, and other undesirables, under puppet-regime-change-face Suharto. For a recent book, see The Jakarta Method ${ }^{1}$.

\section{PRIMARY SOURCES : (HACKER) MAGAZINES}

— Phrack e.g. "The art of port scanning". 1997, issue 51.

Brought nmap to wider attention a few years before its Matrix appearance.

when working to scan massive networks. The tool, nmap, supports

- vanilla TCP connect() scanning,

- TCP SYN (half open) scanning,

- TCP FIN (stealth) scanning,

- TCP ftp proxy (bounce attack) scanning

- SYN/FIN scanning using IP fragments (bypasses packet filte

- UDP recvfrom() scanning,

- UDP raw ICMP port unreachable scanning,

- ICMP scanning (ping-sweep), and

- reverse-ident scanning.

The freely distributable source code is appended to this paper.

\section{[ Introduction ]}

Scanning, as a method for discovering exploitable communication been around for ages. The idea is to probe as many listeners as keep track of the ones that are receptive or useful to your part

\section{- bOING bOING}

A mostly forgettable magazine that was never able to approach Reality Hackers/Mondo in any way, neither in format, nor in content, contributors, nor marketing, nor durable influence. (their parody of Mondo led to a large irony - being that this publication increasingly started to look like Mondo itself during its last years, see in part. \#13, 14 covers... ) Collaborators -shared with Mondo- : Bruce Sterling, Gareth Branwyn, Jon Lebkowsky, Paco Xander Nathan...

\footnotetext{
${ }^{1}$ Hobsbawm seems to have next to nothing to say about Sukarno, in The Age of...
} 


\section{- FringeWare}

A very interesting, later Southern magazine from Austin - computers and fringe culture, a la Mondo - mixing cultural articles (e.g. "Sources of things Gothic" from the King James Bible to Neil Gaiman) and more technical ones (e.g. UNIX, Usenet, newsgroups on UFOs...) as well as collage art work, album reviews, short comics...
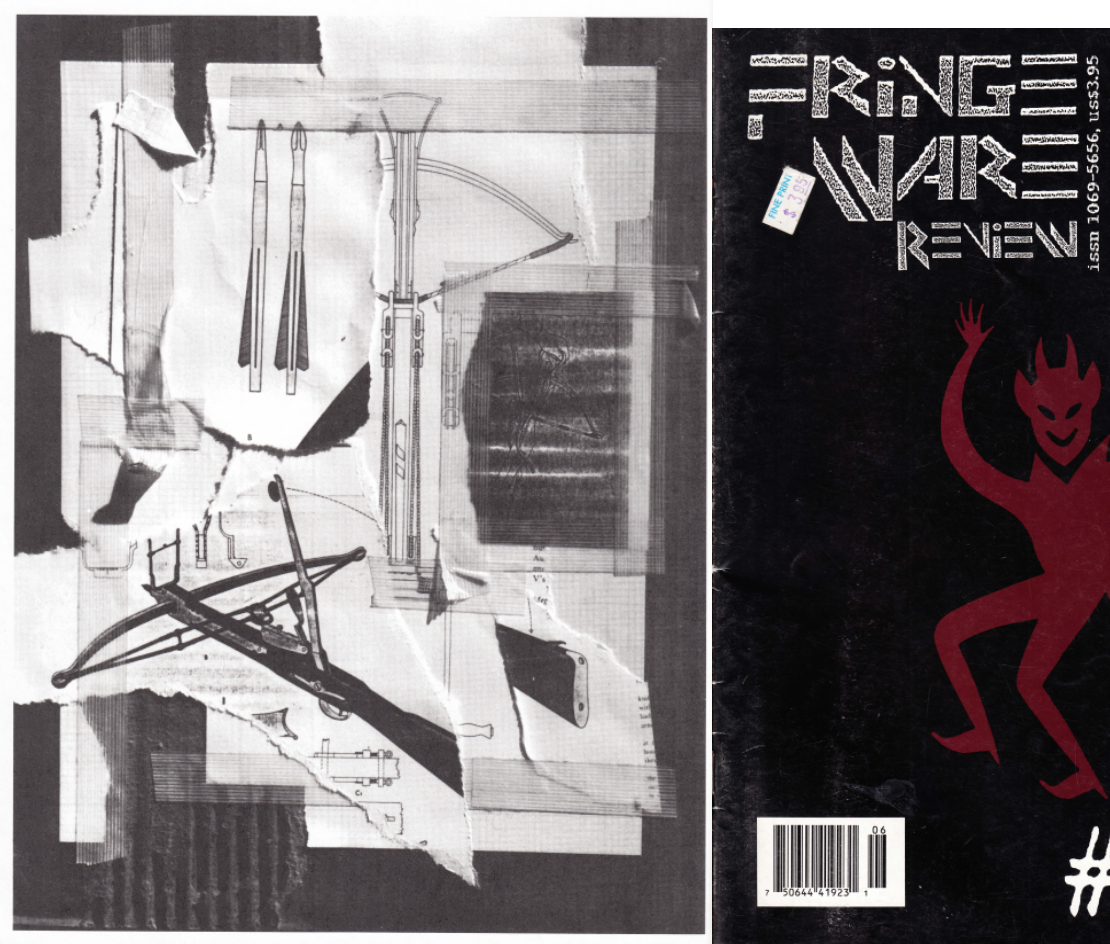

Stealing the fire from Heven (\$13.31 + 51.00 sth $\quad$ state of mind. And if you think that Jesus could just like I am, but if I hadn't been a Thelemite
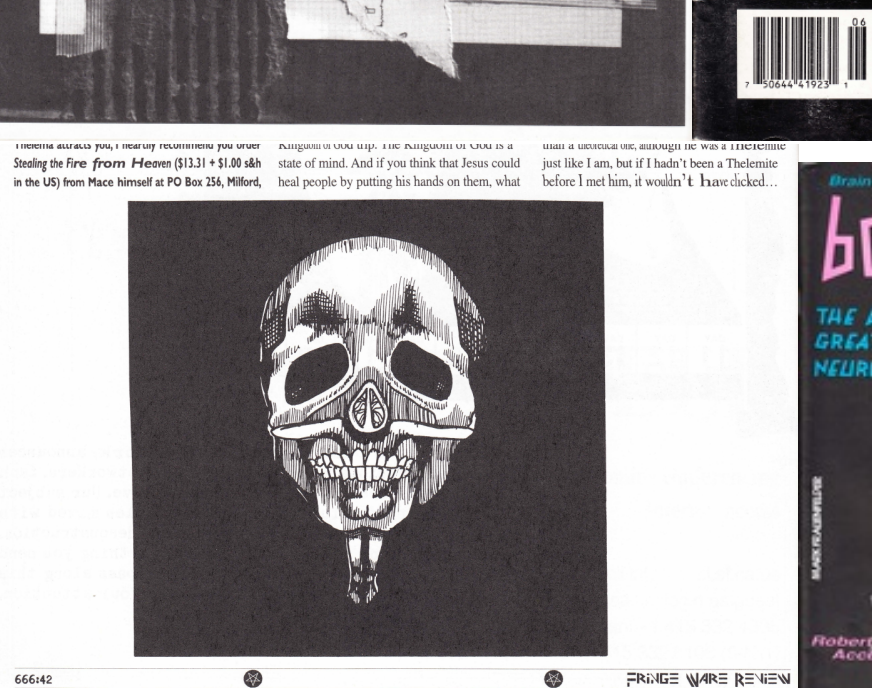

\section{\#6(66)}

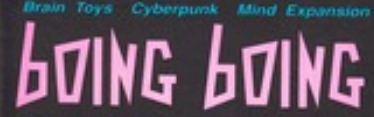

Illustration : FringeWare 6 / bOING bOING 6

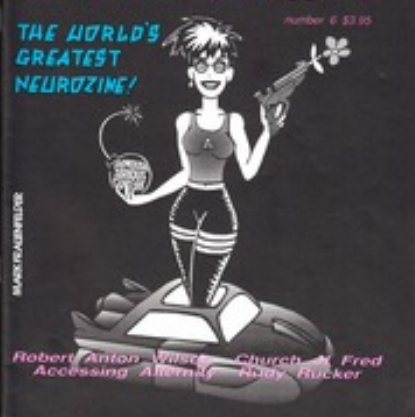




\section{FILM}

- Cronenberg. 1983. Videodrome

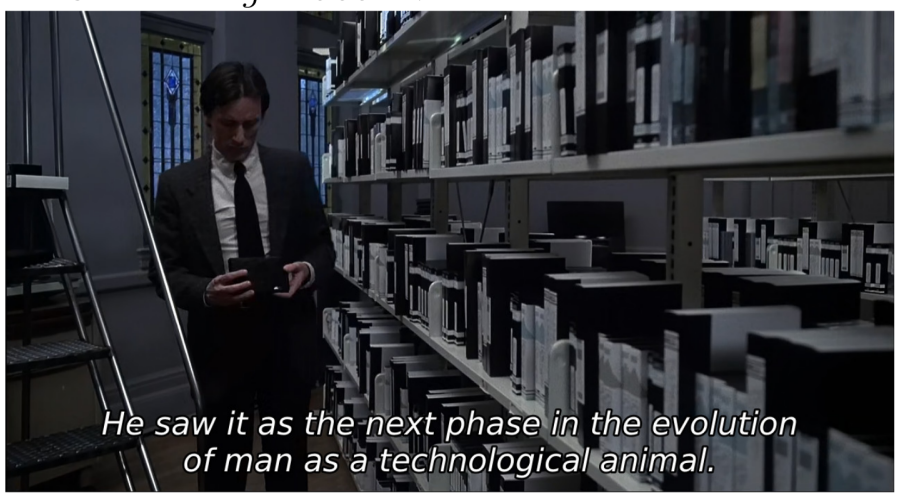

Similar technology-oriented conspiracy films include Three Days of the Condor (1975), or The Parallax View (1974) by Pakula, best known as the director of All the President's Men.

\section{PRIMARY SOURCES : SOFTWARE DOCUMENTATION}

- PGP 1.0 documentation

Open question, controversy : was PGP "proprietary" upon first release?

e.g.,

http://openpgp.vie-privee.org/manupgp1.htm ("Wednesday, June 5, 1991 2:28 pm") https://pgpkeys.org/docs/pgp10.guide.txt ("Thursday, April 30, 1992 7:43 am")

"PGP is not shareware, it's freeware. Published as a community service."

The revised 1.0 guide from 1992 inserts between the two sentences "Forbidden freeware."

GPL is included but various deviations occur ("Regardless of and perhaps contrary to some provisions")

The preambule (Why Do You Need PGP?) seems to also have undergone modifications. It specifies the background for the software : "Senate Bill 266, a 1991 omnibus anti-crime bill" introducting backdoors in secure communications.

\section{PRIMARY SOURCES : SHOVELWARE}

An antiquitated practice from the 1990 's, (when the internet was still exceptional, hence their value), which now are wonderous archives for historians.

http://cd.textfiles.com/megarom/megarom2/MISC/MISC/ ( PGP10.ZIP 73.4 KB )

http://cd.textfiles.com/tigershareware/x10/ ( pgp10.zip 73.6 KB) $\ldots$ 


\section{ALTERNATIVE CULTURES : MANGA, INDIE VIDEO GAMES}

- Nihei, Tsutomu. BLAME!

Representative art work, in the cyberpunk genre. Notable for its landscapes (vast, dystopian, vertical structures). The mind's content, memories are information and thus suceptible to data treatment (access, download, viruses, ...).
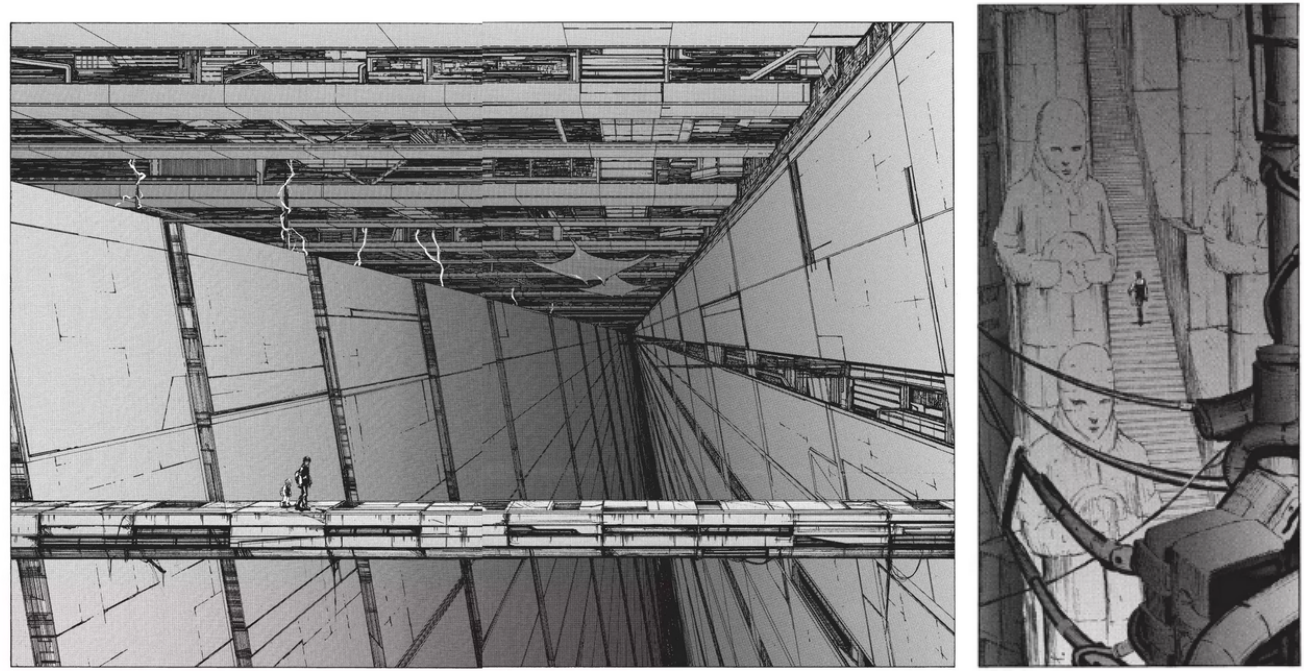

The first chapters, whose titles are evocative of 1990s' cyber culture, have been collected in a single volume and should provide a good introduction.

[The creator of Dorohedoro was an assistant? Common styles ie backgrounds]

- VA-11 HALL-A: Cyberpunk Bartender Action (2015)

Created by a team from Latin America, this work mirrors their own experiences of poverty, chaos, and survival in the modern, urban, atomatic world.

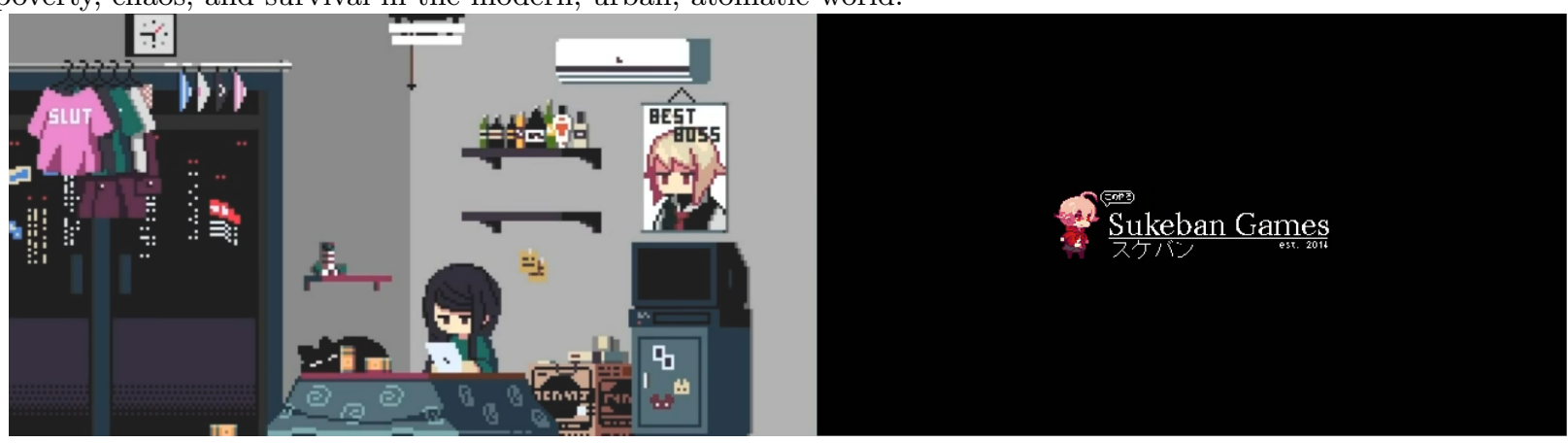

A life simulation, including regular news broadcasts like " Mass emigration continues", "inflation rates"... Information about the world is also apprehended through interactions with guests and co-workers of the bar.

Do you believe all that stuff about tensions growing? 